\title{
POSSIBILITIES AND LIMITS OF SYNTHETIC APERTURE RADAR FOR SNOW AND GLACIER SURVEYING
}

\author{
by \\ H. Rott \\ (Institut für Meteorologie und Geophysik, Universität Innsbruck, Austria) \\ and \\ C. Mätzler \\ (Institut für angewandte Physik, Universität Bern, Bern, Switzerland)
}

\begin{abstract}
The physical background for the interpretation of microwave measurements on snow and ice is summarized. The angular and spectral behaviour of backscattering is shown for various snow types based on measurements carried out in the Swiss Alps. The information content of SAR images in regard to snow and glacier applications is discussed, and examples are shown for Seasat SAR and airborne SAR images. The preliminary specifications are given for an optimum SAR system for snow and glacier monitoring. The main advantage of SAR is due to its weather independence; for special applications the SAR information on the physical state of snow and ice may be of interest. Future SAR sensors can become important components in a snow and glacier monitoring system, but in order to fulfil all tasks, high-resolution optical sensors and improved passive microwave sensors will also be required.
\end{abstract}

\section{INTRODUCTION}

Spaceborne synthetic aperture radar (SAR) systems are of considerable interest for snow and glacier monitoring because of the capability to penetrate clouds and because of the high spatial resolution. So far, only experimental SAR systems have been operating in space, but, from the year 1989 onward, various SAR sensors for earth observation are due to be launched. In order to learn about the possibilities of SAR for snow and glacier applications, detailed investigations have been carried out based on airborne and spaceborne SAR data and on radar image simulations. Ground-based scatterometer measurements and theoretical considerations provided the basic information on the backscattering properties of snow and ice. The investigations resulted in the preliminary definition of a spaceborne SAR system for snow and glacier monitoring and in an assessment of the SAR potential for various scientific and operational applications.

\section{BASIC CONSIDERATIONS ON BACKSCATTERING OF SNOW AND ICE}

To understand the microwave signatures of snow cover lying on the ground or on an ice surface, it is essential to know which layers are contributing to backscattering. In the case of a semi-transparent medium such as snow, the power attenuation of a propagating wave is described by the volume extinction coefficient $k_{e}$ or its reciprocal value, the penetration depth $\delta_{\mathrm{p}}=1 / \mathrm{k}$. For dry snow $\delta_{\mathrm{p}}$ is in the order of $10 \mathrm{~m}$ at $10 \mathrm{GHz}$ and decreases to about $1 \mathrm{~m}$ at $40 \mathrm{GHz}$ (Rott and others, 1985). The presence of liquid water strongly increases the dielectric losses. $\delta_{\mathrm{p}}$-values for wet snow with liquid water content of $2-4 \%$ by volume are typically of the order of one wavelength only.

The significance of wetness for the interaction of microwaves with the snow cover is evident in Fig.1, which shows the results of measurements carried out at Weissfluhjoch on 10 and 11 April 1980. The site was covered with $1.9 \mathrm{~m}$ of snow, the total water equivalent was $0.60 \mathrm{~m}$; the snow temperatures were between $-1^{\circ}$ and $-2^{\circ} \mathrm{C}$ except for the top $20 \mathrm{~cm}$, where the temperature varied between $0^{\circ}$ and $-18^{\circ} \mathrm{C}$. Melting took place during the noon and early afternoon hours, the maximum column height of liquid water was $0.17 \mathrm{~mm}$ on 10 April and $\geq 1 \mathrm{~mm}$ on 11 April when it was warmer and the sky was clear. However, the top millimeters of the snow cover remained frozen during the days because the air temperature was clearly below $0{ }^{\circ} \mathrm{C}$. The active and passive microwave signatures are strongly influenced by the diurnal variation of wetness in the surface layer. Blackbody properties are approached when the surface layer is wet, resulting in high emission and low backscattering values. The differences in the minimum value of the backscattering coefficient $y$ between 10 and 11 April are related to differences in snow wetness. During the night penetration of the microwaves increases significantly and scattering in the snow pack is effective, for the longer wavelength ( $\gamma$ at $10.4 \mathrm{GHz}$ ) scattering at the ground/snow interface is important. $\gamma$ is related to $\sigma_{0}$, the scattering cross section per unit surface area, by $\gamma=\sigma_{0} / \cos \theta$, where $\theta$ is the angle off nadir.

The radar return signal from glacier ice is dominated by surface scattering which is dependent on surface roughness in relation to the wavelength. The radar return from snow-covered targets may include contributions from scattering at the air/snow boundary and at internal inhomogeneties and boundaries. For wet snow, scattering at the surface and in the uppermost snow layer is effective.

Calculations of scattering from snow and ice in dependence of various physical parameters are of great importance for the analysis of radar data, because only limited measurement data are available. However, accurate modelling of the scattering behaviour of snow and ice surfaces is a difficult task because the characteristic dimensions of the surface roughness are similar in magnitude to the radar wavelengths. Roughness measurements of wet snow at an Alpine test site revealed rather gentle undulations with auto-correlation lengths of surface height of several centimeters, allowing application of the Kirchhoff method for backscatter calculations at X- and $\mathrm{C}$-band wavelengths for the surface scatter contribution (Rott 1984[a]). For the reflectivity at horizontal polarization also the simple Fresnel formula provides good results (Mätzler and others 1984).

Due to the characteristic roughness features, the problem of surface scattering from glacier ice is of great interest, but so far thorough theoretical and experimental investigations are lacking. Measurements of small-scale surface roughness on an Alpine glacier revealed bimodal frequency distributions of surface height for melting glacier ice with cryoconite holes. In addition to small-scale roughness, surface undulations in the horizontal scale of 


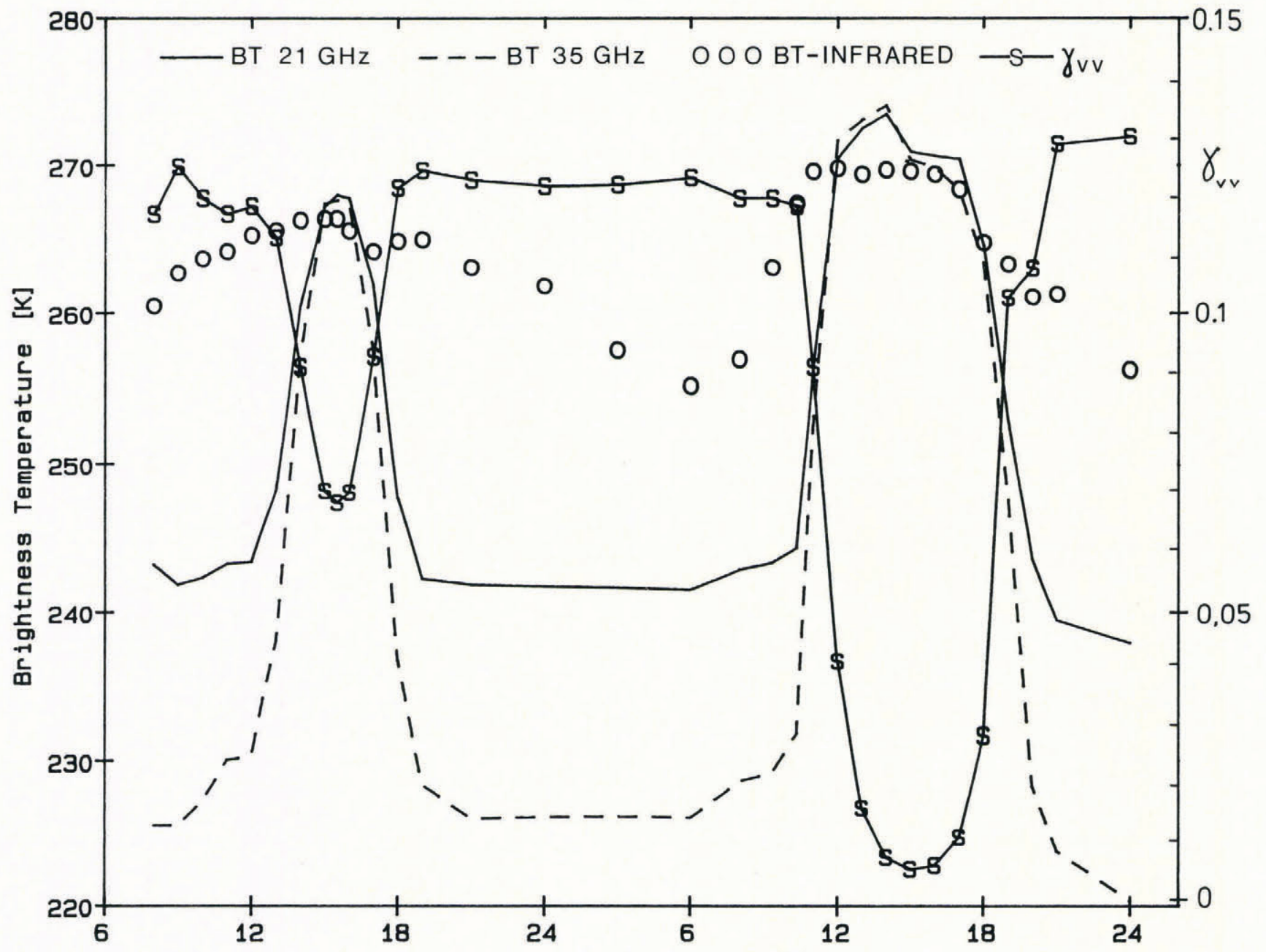

Time after 10-Apr-80 0: 00 [Hours]

Fig.1. Temporal variations of brightness temperatures $\mathrm{BT}$ at $21 \mathrm{GHz}$ and $35 \mathrm{GHz}$ in vertical polarization, of infrared brightness temperature, and of the backscattering coefficient $\gamma$ vv at $10.4 \mathrm{GHz}$, all at $40^{\circ}$ off nadir, measured over snow cover on Weissfluhjoch, Switzerland, on 10 and 11 April 1980.

meters to tens of meters are typical. Generally the roughness of the ice surfaces is significantly higher than the roughness of snow surfaces, resulting in higher radar return (Rott 1984[a]). However, in relation to longer wavelengths (e.g. L-band), glacier ice surfaces sometimes appear smooth and show low backscattering. Surfaces of superimposed ice are frequently smooth; this may cause problems for discrimination against wet snow.

For a dry snowpack, the contribution of surface scattering is small; scattering at snow grains and at internal layers dominates. The wavelengths of the earth observation radars are significantly larger than the diameters of the individual snow grains. For calculating the volume scattering contribution, the Born approximation can be applied, in which the dielectric constant $\epsilon$ is considered as a function of position and is described by a stationary mean part $\bar{\epsilon}$ and a randomly fluctuating part $e_{f}$ For closely packed scatterers, a modification to the Born approximation was derived, applying an exponential autocorrelation function for the amplitude of $\epsilon_{\mathrm{f}}$ (Mätzler 1985). The calculations show that volume scattering increases with the frequency $f$ according to $\mathrm{f}^{4}$ for low frequencies, similar to Rayleigh scattering, but in the case of dense packing of the irregular ice grains the exponent is slightly reduced.

The main conclusions for the interpretation of radar images are summarized as follows. Due to high dielectric losses, wet snow cover is characterized by low return; only the uppermost layer contributes to backscattering. High return is only observed at angles of specular reflection. Dry snow is transparant at $\mathrm{L}$ - to $\mathrm{X}$-band frequencies $(0.4$ to $11 \mathrm{GHz}$ ). If dry snow is lying on soil, the scattering contribution of the snow/soil interface dominates the radar signals. Therefore the detection of dry snow is hardly possible. Higher microwave frequencies (>15 GHz) may be useful for mapping dry snow because of the increase in volume scattering, but presently no earth observation radars are planned at these frequencies.

If the thickness of a dry snow pack is in the order of many meters to tens of meters, as in dry accumulation zones of glaciers and ice sheets, a strong return signal can be observed, because the absorption is low and a thick layer contributes to backscattering. In this case not only the snow grains act as scatterers, but also internal interfaces due to density variations may be effective. Layers of thick, refrozen crusts can substantially increase the backscattering at $\mathrm{X}$-band and higher frequencies (Reber unpublished). If a comparatively thin layer of dry snow is lying on glacier ice or on a wet snow pack, the return signal from these surfaces will only be slightly modified by the dry snow pack. This offers the possibility to detect the boundary between snow and ice areas on glaciers through a layer of fresh snow.

\section{GROUND-BASED BACKSCATTERING MEASUREMENTS}

Systematic measurements of microwave emission and backscattering from an Alpine snow pack have been carried out for several years at the Swiss test site, Weissfluhjoch 


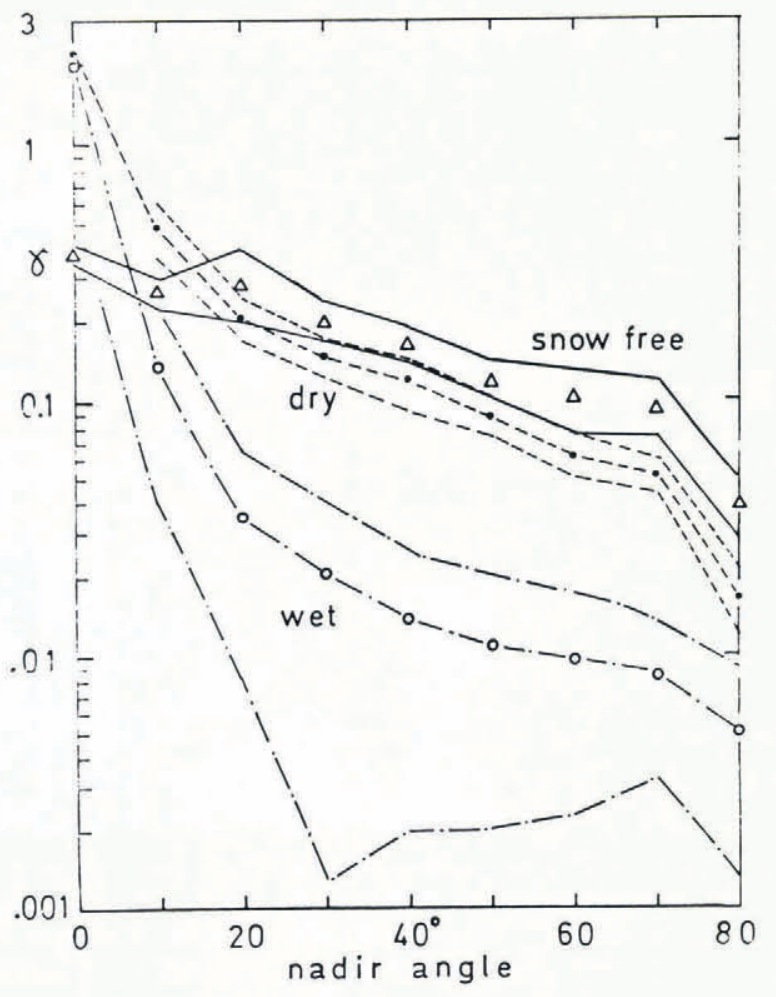

Fig.2. Backscattering coefficients $\gamma$ at $10.4 \mathrm{GHz}$ (mean values of $\mathrm{hh}$ and $\mathrm{vv}$ polarizations) versus nadir angle measured at the test site, Weissfluhjoch, for the dry snow, wet snow, and snow-free situations. The symbols represent the mean values, the lines the standard deviations resulting from different target conditions.

(Mätzler and others 1982; Mätzler and Schanda 1984). Fig.2 summarizes the results of the backscatter measurements conducted with a noise scatterometer operating in the $\mathrm{X}$-band (at $10.4 \mathrm{GHz}$ ). The mean values and standard deviations of the backscattering coefficient in parallel polarizations ( $\mathrm{hh}$ and $\mathrm{vv}$ ) are shown for incidence angles between 0 and 80 degrees off nadir for the snow-free test site, for dry snow, and for wet snow. At incidence angles $\geq 20^{\circ}$ the backscattering coefficient of wet snow is on the average ten times smaller than for snow-free ground. When the ground is covered with dry snow, the differences from the snow-free site are small. Only at vertical incidence, where specular reflection at the snow surface and internal interfaces dominates, the backscattering coefficient is higher for all types of snow cover.

The highest relative variability of backscattering was observed for the wet snow cover. This is primarily an effect of variations in surface wetness and grain size and secondly due to surface roughness variations. Relative variability of $\gamma$ for the snow-free site with a rough surface and for dry snow cover was smaller. For the dry snow measurements, a weak decrease in $\gamma$ was observed with increasing snow-water equivalent (Mätzler 1986). Ulaby and Stiles (1980), on the other hand, measured a clear increase of $\gamma$ at $9 \mathrm{GHz}$ and $57^{\circ}$ incidence angle, when dry snow was piled up over a smooth surface. This points out the importance of the surface below a dry snow pack for the intensity of backscattering. The frequency dependence of backscattering in the S- to X-band range for various snow conditions is illustrated in Fig.3. The measurements were taken in an Alpine valley in spring 1985 (Hüppi 1986). The dry snow situations (curves 1 and 3 ) show little differences in $\gamma$ compared with the snow-free site, a mown meadow. Melting of a thin surface layer during the days 25 and 26 February results in a clear decrease of $\gamma$ at frequencies $>5 \mathrm{GHz}$. The completely wet snow pack gives the lowest signal; the contrast to the snow-free site is optimum in the $\mathrm{X}$-band range.

When the results of the scatterometer measurements are applied to radar image analysis, additional factors have to
HH Polarisation 50 deg Nadirangle

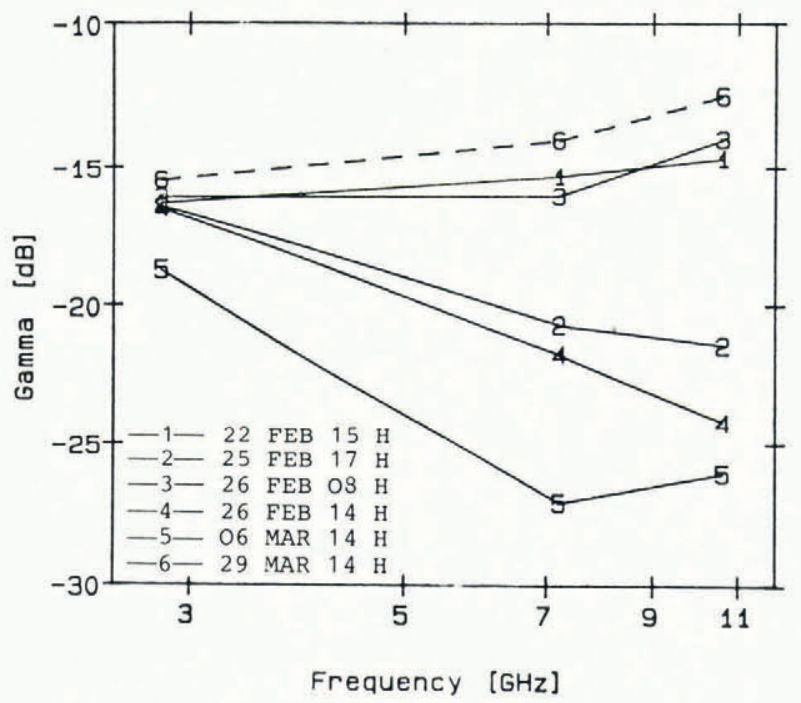

Fig.3. Backscattering coefficient $\gamma$ versus frequency for various snow-cover situations measured in an Alpine valley between 22 February and 29 March 1985. (1) dry snow of $50 \mathrm{~cm}$ depth, (2) and (4) slightly wet snow, (3) refrozen after situation 2, (5) wet snow of $25 \mathrm{~cm}$ depth, and (6) the snow-free site (from Hüppi 1986).

be taken into account. One problem of radar imagery is the limited radiometric accuracy because of speckle effects and difficulties of calibration. Other problems are related to the spatial variability of the physical properties of natural targets. This means that clear discrimination of two targets is only possible if an appreciable contrast in the mean backscattering intensities is observed. For wet snow cover, good contrast can be expected in the frequency range between about 5 to $15 \mathrm{GHz}$. At lower frequencies many natural surfaces appear smooth, similar to the snow cover (Rott and others 1985).

\section{RADAR IMAGES OF SNOW AND GLACIERS}

Available spaceborne SAR images of snow and glaciers are limited to L-band data, which have been acquired at $1.28 \mathrm{GHz}$ by the Seasat SAR system and Shuttle Imaging Radars SIR-A and SIR-B. The look angle of the Seasat SAR antenna was 20 degrees off nadir, which is not suitable for application in areas with high relief because of geometric distortions and layover effects. However, in areas with gentle topography the Seasat SAR was found quite useful and a large number of good images of glaciers was acquired by Seasat during its 3 months of operation in 1978. SIR-A and SIR-B were short-term missions and data were taken only over a few glacier-covered areas. The antenna look angle of SIR-A ( $47^{\circ}$ off nadir) was adequate for imaging in mountainous regions, the look angle of SIR-B was selectable between $15^{\circ}$ and $60^{\circ}$. Airborne SAR experiments were carried out to investigate the SAR capabilities for mapping the seasonal snow cover.

Fig. 4 shows a SAR image of the northern part of the Langjökull ice cap in Iceland which was acquired by Seasat on 24 August 1978. The nominal spatial resolution of the SAR was $25 \mathrm{~m}$ with 4 looks averaged, the swath width was $100 \mathrm{~km}$. The altitude differences in the area are not very large; the glacier extends from about $800 \mathrm{~m}$ to $1300 \mathrm{~m}$ a.m.s.l. The central part of the firn plateau shows low radar return, corresponding to wet snow with a smooth surface. The intensity of the return is increasing at the lower parts of the firn area and reveals similar values to those of glacier ice. This behaviour can be explained by increasing roughness of the snow surfaces at lower altitudes. According to theory, the scattering contribution from the surface is dominant in the L-band at incidence angles below at least $40^{\circ}$. Along the boundary of the snow area a zone of very low return appears. This corresponds to the signature of 


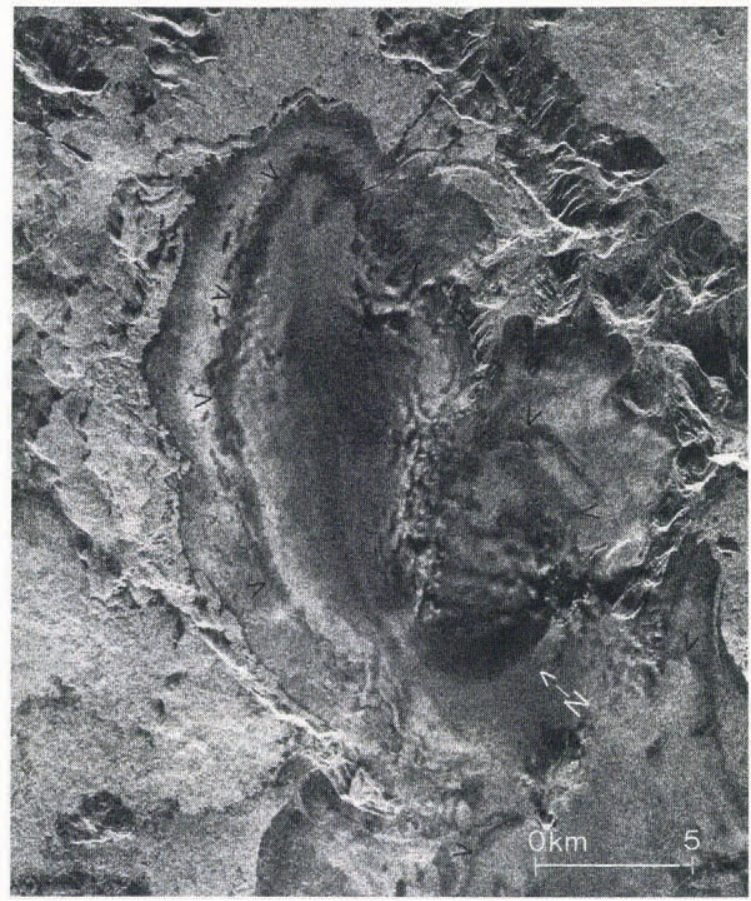

Fig.4. Part of Seasat SAR image of Iceland acquired on 24 August 1978, showing the northern part of the Langjøkull ice cap, processed at DFVLR, Oberpfaffenhofen, Germany. SAR look direction is from bottom to top. The black arrows point to the snowline on the glacier.

very wet snow or slush which reveals high dielectric losses due to the water content. The interpretation of brightness differences in the image is further complicated by variation in backscattering due to topographic effects. This example shows clearly that textural information is essential for the discrimination of snow and ice areas. Similar characteristics of backscattering were observed in Seasat images of other glaciers in Iceland (Rott 1984[a]).

If we look at radar images from high mountain areas, effects of imaging geometry are dominant, the slope orientation relative to the antenna being of main importance for the strength of the return signal. SIR-A acquired an image swath over the Karakoram mountains in Pakistan, where the large glaciers cover altitude ranges of more than $3000 \mathrm{~m}$. The main glacier streams can be easily identified in these images due to their characteristic dendritic shape. However, it is hardly possible to derive information on ice or snow cover on steep slopes or to delineate the glacier boundaries in the accumulation zone. An interesting feature on the glaciers is the high return signal of the dry firn zones at high altitudes, which results in strong contrast to the wet firn areas with low return (Rott 1984[b]).

Airborne SAR images of seasonal snow cover were acquired in the X-, C-, and L-bands at Alpine test sites in Switzerland (Mätzler and Schanda 1984) and Austria (Rott and Domik 1984) in June and July 1981 during the European SAR-580 experiment which was conducted by the European Space Agency and by the Joint Research Centre of the European Communites. Fig.5 shows an evaluation from the SAR data of the Austrian test site in the Ötztal mountains; the antenna incidence angles range from $60^{\circ}$ to $65^{\circ}$ off nadir across the swath shown. The lower part of the Figure shows a window of the $\mathrm{X}$-band radar data after application of a $5 \times 5$ pixel low-pass filter. In this enlargement the speckle structure is still visible in spite of filtering of the original single-look data, which had a nominal resolution of $3 \mathrm{~m} \times 3 \mathrm{~m}$.

The snow cover was wet at the time of the SAR overflight, and the average liquid water content was $6 \%$ by volume. This resulted in low radar return in the X-band, which enables clear discrimination against the snow-free surfaces. If a limited area with little variation of incidence

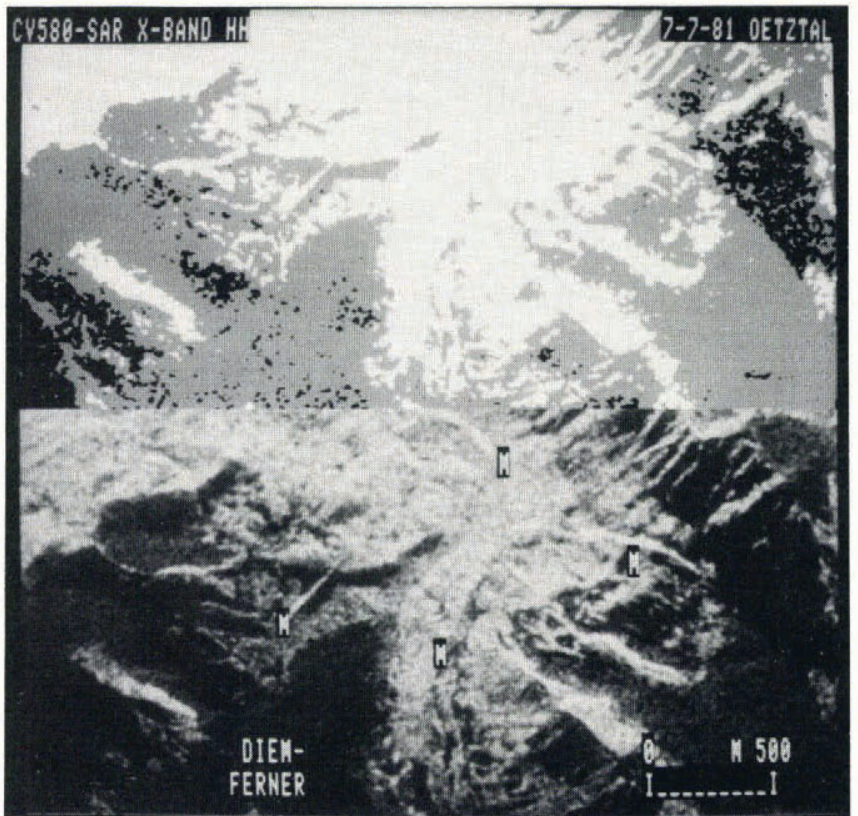

Fig.5. Evaluation of digital airborne SAR data, acquired on 7 July 1981 over the Austrian SAR-580 test site. Lower image: display of digital SAR data after $5 \times 5$ pixel lowpass filtering (radar illumination is from top to bottom). M = moraines from historic glacier advances. Upper image: map of snow extent by density slicing. White = snow-free; grey $=$ snow; black $=$ radar shadow .

angles is considered, the discrimination of snow-covered and snow-free areas is possible by application of simple densityslicing methods as shown in the upper part of the figure. In some cases ambiguities were found between radar shadow and snow, because the transmitter power of the radar system was low. For machine classification over larger mountain areas, the variations in signal strength due to the local incidence angle of the radar beam have to be taken into account. This requires more complicated techniques such as matching of real and simulated images (Rott and Domik 1984). Quantitative analysis of the airborne SAR data indicated that the contrast between wet snow cover and snowfree surface decreases from X-band to longer wavelengths; the same is true for the discrimination of snow and ice areas on glaciers (Rott 1984[a]) and was also found by ground-based scatterometer measurements (Hüppi 1986).

\section{CONCLUSIONS}

Concerning snow and glacier applications, the main advantage of SAR compared to imaging sensors in the visible and near infrared is the all-weather capability. For mapping wet snow cover, an X-band system may be considered optimum; a C-band system should also be useful. It is questionable if SAR can be applied for mapping a thin layer of dry snow. According to our present knowledge dry snow mapping would require a dual-frequency system with one frequency in the $\mathrm{X}$-band and the second frequency $\geq 18 \mathrm{GHz}$. More research is needed on this topic to come to firm conclusions. Radar image simulations were carried out to learn about the requirements in imaging geometry. For snow mapping in mountain areas, antenna look angles between 40 and 50 degrees and spatial resolutions of 15 to $20 \mathrm{~m}$ are needed (Rott and others 1985). The spatial resolution has to be higher than for optical sensors, because spatial averaging is needed for the SAR data to reduce the speckle effects.

Considering the glacier applications, SAR will be of main interest for those tasks which require frequent coverage or regular repetition. Due to the imaging geometry, glacier mapping by SAR is problematic in areas with high relief. Generally, for glacier mapping high-resolution optical sensors such as Landsat-TM or SPOT are preferable. However, for monitoring fast-changing glaciers, a weather 
independent system may be needed. Also over the polar ice sheets SAR systems are able to fulfil important complementary tasks such as mapping of ice shelf boundaries and of surface flow features.

Snow and bare ice areas on glaciers usually can be discriminated in SAR images, though it is of ten more difficult than in multispectral optical imagery. If the equilibrium line is within the snow area, the detection by SAR will be hardly possible, whereas differences in snow reflectivity of ten make it visible in optical imagery. On the other hand, microwave sensors offer some advantages due to the penetration of snow. Thus SAR may enable the detection of the boundary between ice and firn through a layer of dry snow in the autumn. In radar images the extent between the wet and dry zones in the accumulation areas can be detected. This is, for example, of interest for investigations of the Greenland ice sheet.

The European Space Agency (ESA) plans to launch a C-band SAR system on the remote sensing satellite ERS-1 in 1990. This system was designed for ocean and sea-ice applications. According to the imaging geometry it will be of interest for glacier applications only in areas with gentle relief. For the nineties, a SAR system for land application is under consideration by ESA; the requirements for snow and land-ice applications have been investigated in a detailed study (Rott and others 1985). The following SAR system parameters were specified for a snow and glacier monitoring system:

\begin{tabular}{|c|c|c|}
\hline $\begin{array}{c}\text { Frequency single } \\
\text { dual }\end{array}$ & $\begin{array}{l}\mathrm{X} \text {-band } \\
\mathrm{X} \text { and } \geq 18 \mathrm{GHz}\end{array}$ & $\begin{array}{c}\text { (for wet snow) } \\
\text { (for dry snow, } \\
\text { prel.) }\end{array}$ \\
\hline Polarizations & hh or vv & \\
\hline Incidence angle & 40 to 50 degrees & (off nadir) \\
\hline Spatial resolution & 15 to $20 \mathrm{~m}$. 1 look & \\
\hline Range of $8^{\circ}$ & $-25 \mathrm{~dB}$ to $0 \mathrm{~dB}$ & $\begin{array}{l}\text { (for X-band } \\
\text { hh, vv) }\end{array}$ \\
\hline $\begin{array}{r}\text { Radiometric } \\
\text { resolution }\end{array}$ & $\begin{array}{l}-20 \mathrm{~dB} \text { to }+5 \mathrm{~dB} \\
3 \mathrm{~dB} \text { for } 15 \mathrm{~m} \times 15\end{array}$ & $\begin{array}{l}\text { (at } 20-30 \mathrm{GHz} \text { ) } \\
\text { (at }-25 \mathrm{~dB} \text { ) }\end{array}$ \\
\hline $\begin{array}{l}\text { Radiometric } \\
\text { accuracy }\end{array}$ & $1 \mathrm{~dB}$ (mean) & \\
\hline
\end{tabular}

Because the launch of a spaceborne SAR system at frequencies $\geq 18 \mathrm{GHz}$ is not under consideration for technical reasons, a supplementary sensor is required for dry snow mapping. Due to the capability for mapping dry snow and its water equivalent, a multispectral imaging microwave radiometer should be included in a snow monitoring system. The main drawback of passive microwave sensors is the limited spatial resolution, which is not better than about $20 \mathrm{~km}$ for present sensors, but in the future can be improved to a few kilometers with acceptable efforts. This should be adequate for large- to medium-scale hydrological applications. The main sensors for glacier applications, in particular for glacier mapping, are certainly high resolution optical sensors; SAR can fulfil important complementary tasks.

\section{REFERENCES}

Hüppi R 1986 S- to X-band signature measurements of snow. In Proceedings of MIZEX-EARSel workshop: Microwave Signatures of Arctic Sea Ice under Summer Melt Conditions, University of Bern, March 1986: 70-81

Mätzler C 1986 Can microwave signatures be used to retrieve the water equivalent of a dry snow pack? In Spectral Signatures of Remote Sensing. Proceedings of 3rd International Colloquium ISPRS: 277-284 (ESA SP-247)

Mätzler C Unpublished Interaction of microwaves with the natural snow cover. (Habilitation thesis, University of Bern, 1985)

Mätzler C, Schanda E 1984 Snow mapping with active microwave sensors. International Journal of Remote Sensing 5(2): $409-422$
Mätzler C, Schanda E, Good W 1982 Towards the definition of optimum sensor specification for microwave remote sensing of snow. IEEE Transactions on Geoscience and Remote Sensing GE 20(1): 57-66

Mätzler C, Aebischer H, Schanda E 1984 Microwave dielectric properties of surface snow. IEEE Journal of Ocean Engineering OE 9(5): 366-371

Reber B Unpublished Volumenstreuung von Mikrowellen an gefrorenem Schnee. (Diploma thesis, University of Bern, 1986)

Rott H 1984[a] Synthetic aperture radar capabilities for snow and glacier monitoring. Advances in Space Research 4(11): 241-246

Rott H 1984[b] The analysis of backscattering properties from SAR data of mountain regions. IEEE Journal of Ocean Engineering OE 9(5): 347-355

Rott H, Domik G 1984 The SAR-580 experiment on snow and glaciers at the Austrian test site. Final report. In European SAR-580 Campaign, JRC, Ispra, Italy. Vol 2: 217-231

Rott H, Domik G, Mätzler C, Miller H 1985 Study on use and characteristics of SAR for land snow and ice applications. Final report to ESA. Innsbruck, Universität Innsbruck (Institut für Meteorologie und Geophysik. Mitteilungen 1)

Ulaby F T, Stiles W H 1980 The active and passive microwave response to snow parameters. 2. Water equivalent of dry snow. Journal of Geophysical Research 85(C2): 1045-1049 